The Spectroscomic Binary Boss 46.-Following the discovery of the variable velocity of this star at Mount Wilson in 1914, Messrs. W. S. Adams and G. Strömberg have made extensive observations, and features of special interest have been revealed (Astrophys. Journ., vol. xlvii., p. 329). The star belongs to the class of spectroscopic binaries in which the calcium lines give values of the radial velocity differing widely from those indicated by other lines. The period is 3.5225 days, and the velocity shown by the hydrogen and helium lines has the remarkably large range of $450 \mathrm{~km}$. per second. The calcium lines have been found to show a variation having the same period, but with the comparatively small range of $20 \mathrm{kml}$. A velocity of $-45 \mathrm{~km}$. for the system is indicated by the lines of hydrogen and helium, and of $-23.5 \mathrm{~km}$. by the calcium lines. These results seem to favour the view that the vapour producing the calcium lines is not in the form of a detached cloud in space, but is involved in the binary system itself. The differing velocities for the system deduced from the two sets of lines are probably not to be wholly interpreted on the basis of velocity. 'The visual magnitude of the star is 6.0 , and the spectral type $B_{3}$.

THE INVASION OF TRENCHES BY RATS. PROF. P. CHAVIGNY has contributed to the Revue Générale des Sciences for July $\mathrm{I}_{5}$ and 30 two very interesting and useful articles on the invasion of trenches by rats. Soon after trench warfare began the trenches were invaded by immense numbers of rats, which caused great damage and almost intolerable annoyance at night. Various measures, such as the use of poisons, infective virus, traps, terriers, etc., were taken to destroy the rats, but with very poor success; and it is shown that this was due to a lack of knowledge of the natural history and habits of the animals concerned.

The rat which invades trenches is nearly always the ordinary brown or Norway rat (Mus decumanus), but in the case of dry trenches the black rat ( $M$. rattus) may be present. These rats sleep in places of retreat or holes during the day; it is at night that they cause all the trouble. The intelligence which they display in overcoming obstacles and avoiding traps, poison, etc., is extraordinary; and it is evident that they possess some means of communicating their knowledge to one another, since any particular means of killing them soon becomes of little use. Prof. Chavigny lays special stress on the fact that they live on exactly the same food as man, and cooked in the same way. Of raw food they can make scarcely any use. For instance, they simply starve if given raw barley. They will gnaw and destroy almost anything that their teeth can penetrate, but what they actually live upon is simply the ordinary human food which they are able to reach, and particularly the remnants from meals. A rat consumes about 30 to 5o grams of food daily, and starvation kills it in about forty-eight hours. It neither lays up stores of food nor hibernates in winter.

As ordinary brown and black rats will not breed in captivity, most of our knowledge as to their rate of reproduction is derived from observations on the albino variety, which breeds readily in captivity. The period of gestation is twenty-one days, and the minimum time between two litters from the same female is sixty-two days. She may have as many as five litters in a vear. A litter consists of about ten. A female at the age of two and a half to three months is capable of producing a litter. The young are very efficiently tended, so that scarcely any die. A simple calculation gives the surprising result that a single pair of rats is capable of producing twenty million descendants within three years.

Reproduction ceases during cold weather, and rats cannot reproduce themselves at all in cold climates. In temperate climates reproduction is at a standstill during the winter. The most important factor limiting reproduction is, however, the supply of nutriment. $\Lambda$ female receiving only sufficient food to keep her in good condition does not reproduce at all, whereas with superabundance of food reproduction proceeds at its maximum rate.

In his second paper Prof. Chavigny describes and discusses the various methods used for destroying rats, and shows that the disappointing results obtained are due to neglect of the fact that multiplication of rats is simply the result of scattering human food within their reach. The essential step in controlling the rat invasions is to prevent the scattering about of remnants of food. For this purpose it is recommended that, where possible, all waste food should be collected and used for pigs. Where this is not possible the waste food should be thrown into pits and covered with earth before nightfall. Prof. Chavigny proposes also that placards should be posted up saying that "he who sows fragments of food will reap a harvest of rats."

\section{THE PROPERTIES OF COPPER.}

THE U.S. Bureau of Standards has recently issued a circular (No. 73) entitled "Copper." It appears that the Bureau is constantly in receipt of requests for detailed or general information concerning the properties, statistics, etc., of metals and alloys. Such information is rarely to be found in systematic form. Generally the different sources of such information are difficult of access, and their accuracy is not always certain. Much information of this kind that is quoted is valueless, either for the reason that the data upon which it is based are incorrect or because they have not been properly interpreted in quoting. Accordingly, the Bureau is planning to issue from time to time circulars on individual metals or alloys with the idea of grouping in them all the most trustworthy information that is available, either from its own tests and investigations or from published records contained in the literature.

These circulars are intended to deal primarily with the physical and mechanical properties of the metal or alloy; all other factors, except a few statistics of production, such as methods of manufacture, impurities, etc., are discussed only in relation to these properties. Copper has been chosen as the first metal for this treatment, partly because much of the accurate information regarding it has been obtained at the Bureau, and partly because our knowledge of its properties is more complete than that of any other metal. Moreover, the commercial forms of copper are characterised by a high degree of purity, e.g. the electrolytic wire bar manufactured in the United States of America contains on an average 99.96 per cent. of this metal, and the Lake wire bar 99.89 per cent. The highest quality brands of English (furnace-refined) copper contain about 99.75 per cent.

Circular No. 73 contains the best established values of various physical and mechanical characteristics of pure and commercial grades of copper, principally at the ordinary temperature. Variations of these properties with changes of temperature are also discussed. There is a useful technological section dealing with casting, deoxidation, working, welding, hardening, electro-deposition, and heattreatment, followed by another discussing the effects of impurities on the physical properties of the metal, and concluding with a brief account of its "diseases." A complete bibliography and typical specifications are

NO, $255 \mathrm{I}$, VOL. IO2] 